\title{
Cultural Contexts of Domestic and Juvenile Violence: A Cross- Cultural Perspective from Germany, Turkey and Norway
}

\author{
Haci-Halil Uslucan *
}

\author{
Faculty of Humanities, University of Duisburg-Essen, Essen, Germany
}

\begin{abstract}
The use of violence by parents in child rearing and acts of juvenile violence, which are often intertwined, up to the present day represent serious developmental, cultural and practical challenges, although the rates of domestic violence show a slight decrease in many European countries. This study examines three selected countries, Norway, Germany and Turkey, on the extent to which experiences of domestic violence and harsh parenting are associated with juvenile violence. For this purpose, 386 German, 386 Turkish and 322 Norwegian juveniles (aged 13 to 20 years) were interviewed at schools in Magdeburg, Germany (in the former GDR), Kayseri (Turkey), and Oslo and Tönsberg (Norway) from June 2001 to April 2002, using a standardised questionnaire with 5-point Likert-rating scales. The scales measured maternal violence within the home, family climate, personal and familial risks and variables of juvenile violence (e.g., acceptance of violence, perpetrating violence, and victimisation). The results of this cross-cultural study show significant differences between the three countries examined here regarding both active juvenile violence and the acceptance of violence. Furthermore, both the experience of domestic violence as well as the climate within the family unit points out remarkable differences. Lastly, the results of multiple regression analyses reveals that the proposed model, in which maternal domestic violence, irritability and gender were the predictors of juvenile violence, could explain a great range of variance, especially among German juveniles.
\end{abstract}

Keywords: Juvenile violence, domestic violence, cross-cultural study, parenting context.

\section{INTRODUCTION}

One of the well-grounded trends of the last fifty years is that domestic violence, particularly violence used against children to correct and modify behavior, has undergone a rapid social change and has decreased (for Germany see Wetzels, 1997; for USAmerican families see Straus \& Mathur, 1996). Insofar, at least for some Western societies, it can be assumed that cultural norms supporting the use of violence and corporal punishment against children have eroded; violence is no longer widely accepted, as was pointed out by exemplary changes in German law ("Gesetz zur Ächtung der Gewalt in der Erziehung": Law proscribing violence as an educational means). Nevertheless, it does not follow that domestic violence towards children as a "social evil" has been completely eliminated; on the contrary, throughout many of the world's societies, corporal punishment is still a common technique of behavioral control.

Clinical as well as developmental psychological studies have found strong evidence that experiencing violence in childhood is responsible for a number of negative developmental outcomes including juvenile delinquency, psychopathology and difficulties with peers. A considerable number of studies have emphasized that a parenting style characterized by

*Address correspondence to this author at the Faculty of Humanities, Department of Turkish Studies, University of Duisburg-Essen, Universitätsstr. 12, D-45141 Essen, Germany; Tel: ++49 2011834909 ;

Fax: ++ 49201 3198331; E-mail: haci.uslucan@uni-due.de violence and threats made children apt to use aggressive behaviour (Patterson, DeBaryshe, Ramsey, 1989). Gershoff (2002) showed in her meta-analysis significant associations between corporal punishment and diverse negative childhood behaviours and experiences such as delinquency and antisocial behaviour. Beside this, corporal punishment is commonly linked to low self-esteem, social incompetence (McCord, 1995) and erosion of the parent-child relationship, which in turn diminishes children's motivation to internalize parental as well as social values (Hirschi, 1969).

It is argued that maltreated children often transfer their aggressive style of interpersonal behaviour not only onto their family but also into their interaction with their peers. Furthermore, when children witness violence in the home between their parents or were punished by them, this could tempt them to regard aggression as an acceptable means of resolving conflicts. McCord (1995) established that both parental aggression and harsh discipline at around the age of 10 years strongly increased the risk of later becoming involved with violence. Concerning their own future partnerships, Wetzels (1997) pointed out that witnessing violence between parents constituted a risk factor for either the maltreatment of a partner or victimisation by their own partners.

Despite the fact that a history of abuse is one of the greatest risk factors in the aetiology of child maltreatment, we should point out that there is not a 
straight pathway from early child abuse to later involvement in violence: early experiences of violence may lead not only to externalizing behaviour, namely to further aggression, but also to internalizing behavioural forms, for example depression and acts of selfharming. Wilmers et al. (2002) showed that children growing up in a family with intimate partner-on-partner violence have a higher risk of victimisation. Notwithstanding this, Simons et al. (1991) found that a child does not perfectly imitate the same specific aggressive behaviours, but adopts more a perceived aggressive style of interaction. If children frequently witnessed violent behaviour between their parents, they thereby learned not only a pattern of conflict resolution, namely that aggression is acceptable in loving relationships within the family (Kalmus, 1984), but they also establish a deep distrust of all social relations inasmuch as loving people can also be cruel. This can sometimes cause weaker self-esteem (Gershoff, 2002).

One of the additional consequences of violence in childhood may the weakening of one's ability to develop strong social bonds (Barnett, Miller-Perrin \& Perrin, 1997). That is, victims have problems with both attaching to caregivers and regulating social interactions. Corporal punishment of a child not only causes immediate harm, it moreover leads to a significant and far-reaching impact upon the child's future competencies and behaviour (Loeber \& Hay, 1997). Corporal punishment had a very modest but significant effect on a young person's psychological maladjustment (Rohner, Kean \& Cournoyer, 1991). Compared to children who were not punished, battered children exhibit lower intellectual and cognitive functioning and have more learning disabilities: for example they score lower on reading and maths tests and are more likely to repeat a grade (Barnett, MillerPerrin \& Perrin, 1997). Despite the statistical controls of other relevant factors like poverty, family instability etc., children who are beaten are often more violent towards their peers than children who do not suffer from victimisation. Presumably they expect refusals and hostility from others and then go on to misinterpret the actions of others in social relationships as being hostile and provocative (Dodge et al., 1984). Due to this confused perception, they may tend to react aggressively, which increases on the other side the aggressiveness of their peers.

Beyond this, the family context is the most proximal and the most influential determinant of juvenile violence, as is indicated by a large body of literature on familial correlates of juvenile violence (Coie \& Dodge, 1997; Loeber \& Stouthammer-Loeber, 1986). Usually the careers of juvenile delinquents begin with being neglected at home with accompanying domestic violence and violence experiences at school (Melzer, 2000). The studies of Lösel and Bliesener (2003) and Uslucan, Fuhrer and Rademacher (2003) have pointed out that both an adverse family climate and a harsh and inconsistent parenting style were the strongest predictors of juvenile violence. Although it is not entirely clear whether the harsh disciplinary practices of the parents were used a priori or were evoked by the children's high level of aggression, previous studies in Germany determined that 10 to $15 \%$ of all parents inflicted severe punishments on their children and roughly $10 \%$ of all children in Germany were victims of parental violence (Engfer, 2000).

Families are usually embedded within a sociocultural system. Therefore, in order to interpret domestic violence adequately, it is necessary to take the cultural context into account. Cultures are orienting structures for socially created and learned standards of human perception and action; they differ substantially with respect to the dominant practices and normative standards of parenting. There is clear evidence that both the prevalence and the reaction to family violence and corporal punishment varies within different cultural contexts (de Anda \& Becerra, 2000; Malley-Harrison \& Hines, 2004). If familial violence and corporal punishment are unquestioningly accepted by a majority of a community and by "significant others" at the level of neighbourhood, village, city etc., then parents may feel justified in using violence. On the other side, parents or children may regard this as normative if they realize that they are not the only victims (Gershoff, 2002). Insofar as it seems to be undisputed that the cultural context, i.e. people's cultural beliefs about the appropriateness of corporal punishment, affects both their parenting style (Darling \& Steinberg, 1993) as well as the extent of the violence. A society can foster violence by tolerating it as an appropriate method of conflict resolution, the transmition of norms and values supporting violent behaviour, especially defined through masculinity and dominance, or conversely, reduce violence by vigorously rejection all violently coercive interpersonal interaction within the home, at school, in the public etc. Thus it is assumed that the impact and interpretation of violence will be different in cultures in which violence is more common. In societies or communities with a high tolerance towards violence, violent parents do not therefore view their actions as inappropriate, or themselves as "bad" parents. 
Based on these consolidated findings, we anticipated in our study that juveniles who were victimised as young children or punished physically by their mothers tended to interpret their social context as being more hostile and threatening and therefore are more apt to react with violence. Concerning domestic violence, we focused in our research on maternal violence as several previous studies demonstrated that parental gender is an important reference figure in using corporal punishment: mothers inflicted a higher percentage of beatings than fathers (Day, Peterson \& McCracken, 1998; Gunnoe \& Mariner, 1997; Nobes et al., 1999; Straus \& Stewart, 1999). This greater frequency of maternal punishment is presumably due to the fact that mothers usually spent more time with their children, having more day-to-day interactions with them which resulted in greater frictions and opportunities for punishment.

Furthermore, it was assumed that differences in the levels of domestic and juvenile violence depended on the degree of cultural as well as societal modernization. Beyond that there exists ethnic or class differences regarding the extent of child maltreatment (Garbarino \& Ebata, 1983). Empirical findings further point out significant differences in the level of domestic violence as a function of region as well as the urban-suburbanrural dimension (Straus, Gelles \& Steinmetz, 1980).

The commonalities between Germany and Norway, two highly industrialised and wealthy countries with an individualistic socio-cultural background in which an independent self-perception is dominant seems to be of a higher degree in each of these countries than in Turkey, a more collectivistic society, which has recently undergone rapid transitions but in which still an interdependent self-perception and subordinating personal goals to the goals of the in-group are dominant (Markus \& Kitayama (1991). Additionally, it is assumed that in more collectivistic cultures where hierarchy, obedience, being "well mannered" and in which conformity with obligatory social norms are emphasised, that parents are more likely to discipline the behaviour of their offspring (Kagitcibasi, 1996). Studies conducted over the last few years showed that violence at the individual as well as the familial and community level was - in comparison with western european societies - more common in Turkish society: (http://www.aile.gov.tr/Arastirma12.htm; http://www.aile.gov.tr/Arastirma18.htm).

Findings drawn from two representative studies done in 2001 and 2003 established an overwhelming prevalence of life-time victimization in Turkey, with percentages varying between $60 \%$ and $76 \%$ (http://www.kriminoloji.com/siddet\%20cocuk.htm). A further study on domestic violence in Turkish families notably revealed the significance of aggression in mother-child-relationships (Hortacsu, Kalaycioglu \& Rittersberger-Tilic, 2003); previous studies of Kagitcibasi, Sunar and Bekman (1988) in Turkey found that physical punishment (and other power assertion techniques of control) were the most commonly used forms of discipline, especially in socially inferior class families.

Along this line of reasoning we would expect that e.g. Turkey and Norway to show greater differences in the extent of violence than would Germany and Norway or Germany and Turkey; furthermore, we would expect higher incidences of domestic violence for Turkey than for Germany and Norway.

On the individual level we focused on irritability as an indicator of a problematic temperament and poor emotional control, referring to previous longitudinal studies in Denmark (Brennan, Mednick \& Mednick, 1993), Sweden (Klinteberg et al., 1993), England and USA (Farrington, 1998), which displayed ample evidence for the link between hyperactivity, attention deficits and involvement with violence. In Germany, Sturzbecher (1997) showed that irritability, understood as an index of the individual activation level for violent acts, is one of the best predictors of juvenile violence.

In addition to cultural differences the present study also set out to investigate age and gender differences in various forms of involvement in aggressive acts. A considerable amount of research suggests that age of onset is an important indicator of risk for juvenile delinquency (Tolan, 1987; Moffitt, 1993). Juvenile violence rates rise abruptly at the age of 13 and then decrease at the age of 20 years (Loeber \& Hay, 1997; Loeber \& Farrington, 1998). Furthermore, one of the most stable findings in developmental psychology is that children's peer-directed aggression is a function of gender; the normative sex role socialization and orientation respectively. There is undisputed evidence that physical and instrumental forms of aggression are more frequently observed among boys than girls and avoidant behaviours are more frequently observed among girls than boys (Björkquist, Lagerspetz \& Kaukiainen, 1992; Parke \& Slaby, 1983; Schwartzman, Verlaan, Peters \& Serbin, 1995). Additionally, boys may also tend to elicit more corporal punishment from parents than girls do (Gershoff, 2002). Based on 
studies in the socialisation patterns of collectivistic and traditional societies (Kagitcibasi \& Sunar 1997), in which dominance and machismo are important aspects of male identity, we would expect, especially for Turkish males, higher rates of violence than for Turkish females.

But being exposed to risks like an adverse familial and peer environment does not inevitably lead to aggression; we have also to take into account which ressources and strengths juveniles have at their disposal ; e.g. high self-esteeem, stable social support etc. can hinder or buffer deviant developmental pathways.

Considering this theoretical background, we focused in this empirical study on the relations between the familial variables like family environment, experiences with violence in childhood (namely being victimised by the mother), personal variables like irritability and the variables specific to juvenile violence including acceptance of violence, engagement in violent activities, and victimisation in peer-contexts. The aim of this study is to highlight the effects of domestic violence and family environment on dimensions of juvenile violence inside different cultural contextes.

Explicitly, we pose the following questions: 1) To what extent are there differences regarding experienced domestic violence in the analysed cultural contexts? 2) To what extent juveniles in different cultures vary in their involvements with their active and passive violence? 3) How apparent are age and gender differences in the rates of violence? 4) Are there substantial differences in the risks and resources of juveniles on the familial and individual level? And 5) what kind of relations exist between the parental context, the resources and risks of juveniles and their violent outcome?

\section{METHOD}

We analysed adolescents aged 13 to 20 in three different cultural milieus (Germany, Turkey and Norway) between 2001 and 2002. They were questioned regarding their family environment, their experiences with domestic violence, their personal irritability and their attitudes towards violence as well as their involvement in violent acts. Thereby, violence was conditionaly defined as behaviour which intends, causes or threatens physical harm to others; psychological harm was for these analyses not considered. We have not confined the concept of domestic violence to violence against women, but rather use it synonymously with child maltreatment. The issue of the data collection dates going back several years cannot affect the results because we were merely interested in the interplay of these psychological aspects within various cultural contexts.

\section{Participants}

\section{German Sample}

The German sample was drawn from a larger sample of 1459 pupils from thirteen different schools and two secondary school-tracks in Magdeburg (Germany). The city of Magdeburg is a small town in the former Democratic Republic of Germany with nearly 200,000 inhabitants at the time of questioning. The area in which we started our investigation, the Northern part of Magdeburg, is one of the regions with a high rate of delinquency. For this study, we randomly picked up the data of 386 participants. 262 (68\%) of them attended a grammar school, 124 (32\%) attended a secondary school.

\section{Turkish Sample}

The participants in the Turkish sample were recruited in the central Turkish city of Kayseri, which is one of the fast growing industrial areas of central Turkey and had round about 500.000 inhabitants at the time of questioning. The questionnaire was administered in two different school tracks (state colleges and denominational schools). A total of 500 pupils were questioned; 458 took part at the study $(91.6 \%)$. For this study we randomly picked up the data of 386 participants. 324 of them attended state colleges (84\%), $62(16 \%)$ of them attended denominational colleges.

\section{Norwegian Sample}

In Norway we questioned about 390 pupils from six different schools in Oslo and Tönsberg. Oslo, the capital of Norway, had nearly 520,000 inhabitants at the time of questioning; Tönsberg is a small town 60 miles away from Oslo with nearly 35,000 inhabitants. Nearly two thirds of the respondents were from Tönsberg $(65.1 \%)$ and one third from Oslo (34.9\%). The participating classes were selected from the schools. Most of the participants (273) attended a grammar school, 44 attended a vocational school and 73 a Waldorf pedagogic school. The Norwegian sample had $16.3 \%$ pupils of foreign nationality who were disregarded in the further analyses. 
Each of the samples cannot claim to be representative for the specific culture because we could not control the sampling procedure at any given time: in Germany we undertook the study in a stressed region; in Norway we were reliant on the allocation of the schools. Insofar, control of the age and gender of participants was not possible at all, and in Turkey we contacted schools with regard to our existing personal relations with these institutions. This may limit the broader applicability of the results.

\section{Instruments}

The reliability of the measurement instruments were satisfactory; most of the scales had reliabilities (Cronbach's alpha) above 0.75. Measures were taken from existing scales. Except for the demographic questions all items reported here were answered on a five-point Likert scale ranging from "strongly disagree" to "strongly agree"; scales that measured the frequency of the presented item ranged from "never" to "always". Indices were calculated as scale means.

Corporal punishment often has different meanings and implications, and this poses especially great challenges for cross-cultural studies. With regard to methodological standards of cross-cultural comparisons (Van de Vijver \& Leung, 1997), the basic necessities of conceptual equivalence, indicator equivalence, survey equivalence and scale equivalence were considered. To make sure that we used the same concept of violence as the juvenile subjects, we translated the test items in each of the languages and proved the semantic fields of the offered items by asking the potential respondents. After a conceptual agreement was made by independent test-persons we designed the final version of our questionnaire. Indicator equivalence in this investigation was not a methodological problem because we used only verbal instructions and testitems. Indicator equivalence can sometimes be a problem in field studies in which investigators need to make sure that different modes of behaviour have a functional equivalence. A further demand of crosscultural comparison, the survey equivalence - which means that participants of each group should have the same familiarity with the test situation - should be taken for granted. It was a paper-pencil study which pupils in each group were familiar with. Finally the demand of scale equivalence, meaning that the values or the characteristics of the measured constructs should be representable on the same scale, was verified. In our study we used violence interval scales for measurement. The existence of a metrical

Table 1: Measurement Scales

\begin{tabular}{|c|c|c|c|c|}
\hline \multirow[t]{2}{*}{ Author } & \multirow[t]{2}{*}{ Scale and Item example } & \multicolumn{3}{|c|}{ Reliability (Cronbach`s Alpha) } \\
\hline & & German & Turkish & Norwegian \\
\hline Sturzbecher (1997) & $\begin{array}{c}\text { Family Climate } \\
\text { Example: I can rely on my family members. } \\
\text { Number of Items: } 9\end{array}$ & 0.87 & 0.85 & 0.87 \\
\hline Strauss (1979) & $\begin{array}{c}\text { Conflict Tactics Scale (CTS); Example: My mother had } \\
\text { beaten me before I was } 12 \text { years old. } \\
\text { Number of Items: } 6\end{array}$ & 0.92 & 0.80 & 0.78 \\
\hline Sturzbecher (1997) & $\begin{array}{l}\text { Irritability } \\
\text { Example: I freak out very quickly. } \\
\text { Number of Items: } 9\end{array}$ & 0.85 & 0.85 & 0.79 \\
\hline Sturzbecher (1997) & $\begin{array}{c}\text { Acceptance of violence } \\
\text { Example: For being respected you have to use violence. } \\
\text { Number of Items: } 5\end{array}$ & 0.85 & 0.77 & 0.71 \\
\hline \multirow[t]{2}{*}{$\begin{array}{l}\text { Olweus } \\
\text { (1993) }\end{array}$} & $\begin{array}{c}\text { Bully/Victim Questionnaire } \\
\text { Engagement in violent acts } \\
\text { Example: How often you have beaten another person? } \\
\text { Number of Items: } 5\end{array}$ & 0.88 & 0.79 & 0.69 \\
\hline & $\begin{array}{c}\text { Victimization } \\
\text { Example: How often you were beaten from another person? } \\
\text { Number of Items: } 5\end{array}$ & 0.82 & 0.78 & 0.72 \\
\hline Covariates & Nationality, Age and Gender. & & & \\
\hline
\end{tabular}


equivalence can be tested by the item-intercorrelations. Here it could be shown that the values were sufficient. The mean values of the item-intercorrelations for domestic violence were $r=0.66$ for the German (G), $r=0.41$ for the Turkish $(T)$ and $r=0.38$ for the Norwegian $(\mathrm{N})$ sample. For the acceptance of violence we had item-inter-correlations of about $r=$ $0.54(\mathrm{G}), r=0.40(\mathrm{~T})$ and $r=0.33(\mathrm{~N})$. The same tendencies could be found for violent behaviour: $r=$ $0.59(\mathrm{G}), r=0.43(\mathrm{~T})$ and $r=0.31(\mathrm{~N})$ and for victimisation in peer-context: $r=0.48(G), r=0.41(T)$ and $r=0.34(\mathrm{~N})$. The corrected Item-total correlations ranged in the German sample in all dimensions of violence far above $r_{i t}=0.50$; in the Turkish sample they ranged from $r_{i t}=0.39$ to. $r_{i t}=0.77$, in the Norwegian sample they ranged - with the exception of two items from $r_{i t}=0.38$ to $r_{i t}=0.59$.

\section{Procedure}

For the Turkish sample, the questionnaire was translated into the Turkish language by the author, who is a native speaker of German as well as Turkish. The wording was controlled regarding semantic correctness and comprehensibility by two independent native Turkish speakers, one of them a Turkish teacher in Germany. Then the questionnaire was retranslated by the author. For the Norwegian sample the questionnaire was translated into the Norwegian language from a native speaker of Norwegian with excellent competencies in German and was controlled regarding semantic correctness and comprehensibility by an independent native Norwegian speaker. The questionnaire was then retranslated to ensure that the item meanings had been retained.

The entire data collection process was undertaken in schools and were administered during the time that school was in session. In each of the studies the participation was voluntary and the data gathering in the questionnaires were anonymous. The questionnaires were self-explanatory, but standard instructions were given; it was also stressed that participants were not being tested and that there were no right or wrong answers. We promised that the responses will be dealt with in a confidential manner and encouraged them to respond in an honest manner. The response rates varied between $52 \%(\mathrm{G})$ and $91 \%$ $(\mathrm{T})$. The low response rates in the German sample may stem from the parental approval requirement; parents with a heightened sensibility towards violence and delinquency in North Magdeburg may have refused to allow their children to participate.
Table 2 gives an overview of the age and gender of the total sample.

Table 2: Sample Description

\begin{tabular}{|c|c|c|c|}
\hline \multirow{2}{*}{ Age: } & German & Turkish & Norwegian \\
\cline { 2 - 4 } & $\mathbf{N}=$ & $\mathbf{N}=$ & $\mathbf{N}=$ \\
\hline \hline 13 & 0 & 20 & 0 \\
\hline 14 & 0 & 62 & 0 \\
\hline 15 & 8 & 93 & 20 \\
\hline 16 & 220 & 90 & 59 \\
\hline 17 & 146 & 87 & 78 \\
\hline 18 & 12 & 34 & 60 \\
\hline 19 & 0 & 0 & 67 \\
\hline 20 & 0 & 0 & 4 \\
\hline Missing (Age) & 0 & 0 & 35 \\
\hline Total & 386 & 386 & 323 \\
\hline Mean Age and & $16,4(0,6)$ & $15,7(1,4)$ & $17,4(1,3)$ \\
\hline Standard Deviation: & & \multicolumn{3}{|l}{} \\
\hline Gender: & $179(46.4 \%)$ & $171(44.3 \%)$ & $171(52.9 \%)$ \\
\hline Male & $204(52.8 \%)$ & $211(54.7 \%)$ & $151(46.7 \%)$ \\
\hline Female: & $3(0.8 \%)$ & $4(1 \%)$ & $1(0.3 \%)$ \\
\hline Missing (Gender) & \multicolumn{5}{|l}{} \\
\hline
\end{tabular}

\section{RESULTS}

First we will describe some of the results on the extent of domestic violence (juveniles as victims of maternal violence) and violence in peer-context (as victims and perpetrators). For this we will present in the next table some representative details. For the sake of clarity, the response categories "sometimes", "often" and "always" were added up.

Concerning the frequency of domestic violence in each group, we can point out that nearly $15 \%$ of the German and Turkish, but less than $1 \%$ of the Norwegian sample were sometimes or always beaten by their mothers.

Regarding victimisation in peer-context, we see the same pattern: nearly $17 \%$ of the German and Turkish, but only $10 \%$ of the Norwegian sample reported frequent victimisations.

Focusing on active violent offences, we have yet a totally different pattern: here the data showed that a rate of $15.4 \%$ German juveniles were frequently involved in violent offences, whereas in the Turkish sample this rate amounted more than $42 \%$. In the 
Table 3: Gender-Specific Frequencies (in \%) of Maternal Domestic Violence, Violence Offences and Victimization in Peer-Context

\begin{tabular}{|c|c|c|c|c|c|c|c|c|c|c|}
\hline \multirow[t]{3}{*}{ Item } & \multirow[t]{3}{*}{ Gender } & \multicolumn{9}{|c|}{ Nationality } \\
\hline & & \multicolumn{3}{|c|}{ German } & \multicolumn{3}{|c|}{ Turkish } & \multicolumn{3}{|c|}{ Norwegian } \\
\hline & & never & seldom & $\begin{array}{l}\text { sometimes- } \\
\text { always }\end{array}$ & never & seldom & $\begin{array}{l}\text { sometimes- } \\
\text { always }\end{array}$ & never & seldom & $\begin{array}{l}\text { sometimes- } \\
\text { always }\end{array}$ \\
\hline \multirow{3}{*}{$\begin{array}{l}\text { My mother had beaten } \\
\text { me }\end{array}$} & Total & 53.7 & 31.4 & 14.9 & 64.0 & 20.8 & 15.2 & 96.3 & 2.8 & 0.9 \\
\hline & Male & 55.4 & 28.0 & 15.6 & 58.4 & 24.7 & 16.8 & 95.9 & 3.5 & 0.6 \\
\hline & Female & 52.0 & 34.3 & 13.8 & 68.3 & 17.6 & 14.2 & 96.7 & 2.0 & 1.3 \\
\hline \multirow{3}{*}{$\begin{array}{l}\text { I was beaten by another } \\
\text { person }\end{array}$} & Total & 43.0 & 39.6 & 17.4 & 48.7 & 34.1 & 17.2 & 40.4 & 48.8 & 10.8 \\
\hline & Male & 33.1 & 45.1 & 21.4 & 25.9 & 46.4 & 27.7 & 36.3 & 55.6 & 8.2 \\
\hline & Female & 51.2 & 34.5 & 14.3 & 66.8 & 24.0 & 9.1 & 45.3 & 40.7 & 14.0 \\
\hline \multirow{3}{*}{$\begin{array}{l}\text { I have beaten another } \\
\text { person }\end{array}$} & Total & 55.9 & 28.7 & 15.4 & 42.3 & 27.1 & 30.6 & 63.5 & 31.0 & 5.5 \\
\hline & Male & 43.5 & 34.5 & 22.0 & 18.3 & 32.3 & 49.4 & 55.0 & 37.4 & 7.6 \\
\hline & Female & 66.5 & 23.6 & 9.8 & 61.5 & 23.1 & 15.4 & 72.8 & 23.8 & 3.3 \\
\hline
\end{tabular}

Norwegian sample just $5.5 \%$ reported higher frequencies of violence.

The gender specific analysis of domestic violence revealed in each cultural group only slight and essentially negligible gender differences concerning victimisation caused by maternal violence. In the German and Turkish sample, boys tended to be more frequently victimised ( $p=.07$ for the Turkish sample but not significant for the German sample); in the Norwegian sample the percentage of girls were higher. Apparent gender differences could be found by the rate of victimisation in peer-context: Here, both in the German as well as in the Turkish sample, the victimisation rate for boys was clearly higher. Only in the Norwegian sample were the opposite tendencies observed: here the rate of victimised girls was nearly twice as much as the boys. Finally, highly consistent gender effects could be observed by the rate of active violent offences. At this point it could be shown that in each sample males were dominant higher involved than girls. As expected, the Turkish (49.4\% vs. 15.4 $\%$ ) sample, but also the German sample (22\% vs. 9.4 $\%)$ show very apparent gender differences as well. Within this context the conclusion that being a male indicates a strong demographic risk factor for becoming a perpetrator is justifiably warranted.

Regarding age as an important category of risk for juvenile delinquency, we first analysed violence in the age-groups of 16 to 18 years in each culture. In focusing on this age group we can take into account the robust finding that experienced domestic violence during the life-stage of 12 to 17 years represents the highest risk for transmission of vioelence (Thronberry, 2009.

The acceptance of violence in the Turkish sample had the most pronounced values, whereas German and Norwegian juveniles accepted less violence, but these differences were not significant. In contrast, striking differences were found in the rate of violent acts: German and Turkish juveniles at the risky age between 16 and 18 had significantly higher values of violent offences. No significant differences between the cultural milieus were found concerning the averages of victimisation rates. But it should be remembered that these values, which were all below $M=2$, are very moderate in each group by a scale range from 1 to 5 .

However, we were not only interested in agespecific violence ratios, but also focused on the relationship of juvenile violence with personal and familial risks; therefore, we confined the analyses not to the high risk age group of 16 to 18 years, but included the whole sample for further considerations. In the next step we compared familial and personal variables for identifying the extent of cultural differences by using a one-way ANOVA.

As Table 4 indicates, juveniles perceived the climate within their families as comfortable and 
Table 4: Mean Scores (M), Standard Deviations (SD), Confidence Intervals (95\%) and One-Way ANOVAs

\begin{tabular}{|c|c|c|c|c|c|c|c|c|c|c|c|}
\hline & \multicolumn{3}{|c|}{ German } & \multicolumn{3}{|c|}{ Turkish } & \multicolumn{3}{|c|}{ Norwegian } & \multirow[b]{2}{*}{ df } & \multirow[b]{2}{*}{$\mathbf{F}$} \\
\hline & M & SD & $\begin{array}{c}\text { Confidence } \\
\text { Interval }\end{array}$ & M & SD & $\begin{array}{c}\text { Confidence } \\
\text { Interval }\end{array}$ & M & SD & $\begin{array}{c}\text { Confidence } \\
\text { Interval }\end{array}$ & & \\
\hline Family Climate & 3.53 & 0.78 & $3.45-3.61$ & 3.79 & 0.89 & $3.70-3.88$ & 3.45 & 0.76 & $3.36-3.53$ & 2,1091 & $17.07^{* * *}$ \\
\hline $\begin{array}{c}\text { Domestic } \\
\text { maternal violence }\end{array}$ & 1.31 & 0.65 & $1.24-1.38$ & 1.49 & 0.64 & $1.43-1.56$ & 1.23 & 0.30 & $1.20-1.26$ & 2,1046 & $19.02^{* * *}$ \\
\hline Irritability & 2.66 & 0.78 & $2.58-2.74$ & 2.76 & 0.96 & $2.67-2.86$ & 2.68 & 0.66 & $2.61-2.75$ & 2,1087 & 1.75 \\
\hline $\begin{array}{l}\text { Acceptance of } \\
\text { violence }\end{array}$ & 1.85 & 0.86 & $1.76-1.94$ & 2.01 & 0.95 & $1.91-2.10$ & 1.71 & 0.66 & $1.64-1.79$ & 2,1075 & $10.36^{* * *}$ \\
\hline Violent acts & 1.52 & 0.69 & $1.45-1.59$ & 1.50 & 0.64 & $1.44-1.57$ & 1.37 & 0.36 & $1.33-1.41$ & 2,1082 & $6.48^{* *}$ \\
\hline Victimization & 1.74 & 0.65 & $1.67-1.81$ & 1.71 & 0.71 & $1.64-1.78$ & 1.65 & 0.46 & $1.60-1.70$ & 2,1084 & 2.01 \\
\hline
\end{tabular}

${ }^{*} p<0.05 ;{ }^{* *} p<0.01 ;{ }^{* * *} p<0.001$

satisfying. Turkish adolescents showed the highest values, followed by Germans and Norwegians. The mean value differences between the three groups were significant $(F(2,1091)=17.07, p<0.001)$; the Post-Hoc Scheffé-test showed no significant mean differences between German and Norwegian juveniles.

The same pattern could be shown for domestic violence: Turkish adolescents exhibited the highest mean values; the differences between the groups were statistically significant $(F(2,1046)=19.02, p<0.001)$, but the Post-Hoc Scheffé-test showed that only the Turkish sample differed significantly from the German and Norwegian sample, whereas no significant mean differences could be detected concerning the domestic violence experiences of German and Norwegian juveniles.

Concerning irritability there were no significant mean differences between the groups, although Turkish juveniles exhibited the highest values.

The acceptance of violence was highest in the Turkish group, followed by German adolescents and least by Norwegians. Although the mean differences between the groups were significant $[F(2,1075)=$ 10.36, $\mathrm{p}<0.001$ ], and in direct comparison (Post-Hoc Scheffé-test), only the differences between the Turkish and Norwegian juveniles were significant.

Regarding violent behaviour, German and Turkish juveniles exhibited similar values, while the Norwegians exhibited the lowest rates. In spite of the significant group differences $[F(2,1082)=6.48, p<0.001]$, there were no substantial differences between Turkish and German adolescents. On the other hand, the greatest differences were between German and Norwegian juveniles.
Finally, the comparison of victimisation in peercontext revealed no mean differences, but the tendencies were the same as with the violent offences: the German juveniles had the highest victimisation rates, followed by the Turkish and the Norwegians. Although not shown in the table, additional analyses indicated that effect sizes concerning the dimensions of juvenile violence were small ( $d$-values between .18 to .35) or - concerning domestic violence - moderate ( $d$ values between .15 to .52 ) between the cultures.

Bivariate correlation analyses between the variables of juvenile violence made clear that the acceptance of violence and active violent behaviour is correlated (Pearsons $r$ ); highly positive especially for both the German $(r=0.51 ; p<.001)$ and the Turkish sample $(r=$ $0.41 \mathrm{p}<.001)$, whereas in the Norwegian sample this link between attitudes towards violence and aggressive behaviour were only moderate $(r=0.29 ; p<.001)$. On the other hand, the correlations between active violence and experiences of victimisation in peercontexts were in each sample demonstrably high $(r=$ $0.59(\mathrm{G}), r=0.52(\mathrm{~T}), r=0.46(\mathrm{~N}) ; p<.001)$, which may be interpreted as there not existing a clear-cut profile of offenders, but rather that juveniles are in some contexts offenders and in some other contexts victims of violence.

The correlations between juvenile violence and the indicators of familial and personal risk factors (see Table 5) revealed that the relationships go in the expected direction for each sample, but they also indicated remarkably high intercultural differences. Concerning domestic violence, the rates of attitudes towards and the involvement in violence acts within each group increases with a simultaneous rise in victimisation at home. These relations, especially for 
Table 5: Correlation Coefficients (Pearson) between Juvenile Violence and Indicators of Familial Resources and Personal Risks (G = German; T = Turkish; N= Norwegian)

\begin{tabular}{|c|c|c|c|c|c|c|c|c|c|}
\hline & \multicolumn{3}{|c|}{ Acceptance of violence } & \multicolumn{3}{|c|}{ Violent acts } & \multicolumn{3}{|c|}{ Victimization } \\
\hline & $\mathbf{G}$ & $\mathbf{T}$ & $\mathbf{N}$ & $\mathbf{G}$ & $\mathbf{T}$ & $\mathbf{N}$ & G & $\mathbf{T}$ & $\mathbf{N}$ \\
\hline $\begin{array}{l}\text { Domestic maternal } \\
\text { violence }\end{array}$ & $.31^{* * *}$ & $.22^{* * *}$ & $.15^{\star *}$ & $.49^{* \star *}$ & $.25^{\star * *}$ & $.19^{* *}$ & $.59^{\star * \star}$ & $.26^{* * *}$ & $.32^{* * *}$ \\
\hline Family Climate & $-.13^{*}$ & -.06 & $-.13^{*}$ & $-.24^{\star * *}$ & $-.16^{\star *}$ & -.11 & $-.32^{* * *}$ & $-.16^{\star *}$ & $-.17^{\star *}$ \\
\hline Irritability & $.29^{* * *}$ & $.40^{\star \star *}$ & $.21^{* * *}$ & $.33^{\star * *}$ & $.34^{* * *}$ & $.29^{* \star *}$ & $.28^{* * *}$ & $.29^{* * *}$ & $.33^{* * *}$ \\
\hline
\end{tabular}

Correlations controlled for age and sex.

${ }^{* \star *}: \mathrm{p}<.001 ;{ }^{* *}: \mathrm{p}<.01 ;{ }^{*}: \mathrm{p}<.05$.

the German sample, between domestic violence and own violent involvement $(r=0.49)$ and victimisation $(r=$ 0.59) were remarkably stronger than in the other samples.

A positive family climate was associated with a lowered acceptance of violence as well as with lower active violence and victimisation. Especially for the German youth cohort, the experienced harmony in their family was closely linked with their attitudes and involvements in violence.

Irritability as a personal risk factor could be checked specifically for the relationship towards attitudes to violence by the Turkish youth $(r=0.40)$. The association between irritability and active violence and victimisation were comparable and significant in each group. The results consistently showed that heightened irritability was accompanied both by a higher involvement in active violence and victimisation.

Stepwise regression analyses (using block-wise forward entry procedure with step 1: familial and personal risks and resources, and step 2: sociodemographic variables (gender and age), which should point out how far dimensions of juvenile violence can be predicted by familial and personal risks, revealed a remarkably high extent of explained variance with this model (with the exception of violence acceptance in the Norwegian sample). The assumptions seem to fit best for the German sample. Concerning the acceptance of violence - as a cognitive prerequisite to active violence - this could be best predicted in each group with personal irritability and gender. For the German sample, domestic violence was a further fitting predictor. That is, boys with low self-control or high irritability were apt to accept violence as a means of conflict-solving. Being victimised at home strengthens this relation. The effects of family climate were in each group, with the exception of victimisation in the German sample, very small and not significant; the effects of age were negligible.

Active violent behaviour could be predicted best in conjunction with irritability and gender in each group, but in the German sample, as well as for accepting violence, domestic violence was the strongest predictor ( $\beta=0.42$ ). German juveniles who were victimised at home were most apt to use violence against peermates.

Table 6: Predicting Violence (Standardised Regression Coefficients) (G = German; $T$ = Turkish; $N=$ Norwegian)

\begin{tabular}{|c|c|c|c|c|c|c|c|c|c|}
\hline & \multicolumn{3}{|c|}{ Acceptance of violence } & \multicolumn{3}{|c|}{ Violent acts } & \multicolumn{3}{|c|}{ Victimization } \\
\hline & G & $\mathbf{T}$ & $\mathbf{N}$ & G & $\mathbf{T}$ & $\mathbf{N}$ & $\mathbf{G}$ & $\mathbf{T}$ & $\mathbf{N}$ \\
\hline $\begin{array}{l}\text { Domestic } \\
\text { maternal } \\
\text { violence }\end{array}$ & $.26^{\star * *}$ & $.13^{\star *}$ & .10 & $.42^{* * *}$ & $.14^{* *}$ & $.13^{*}$ & $.52^{* \star *}$ & $.19^{* *}$ & $.24^{* * *}$ \\
\hline Family Climate & .00 & .00 & -.06 & -.05 & -.09 & -.01 & $-.12^{* *}$ & -.08 & -.05 \\
\hline Irritability & $.24^{\star * *}$ & $.36^{* * *}$ & $.18^{* * *}$ & $.24^{* * *}$ & $.28^{* * *}$ & $.26^{* * *}$ & $.16^{\star \star *}$ & $.22^{* * *}$ & $.26^{\star * *}$ \\
\hline Sex & $-.21^{\star \star *}$ & $-.16^{\star \star}$ & $-.15^{\star}$ & $-.20^{\star * *}$ & $-.28^{\star * \star}$ & $-.30^{\star * *}$ & $-.17^{\star \star \star}$ & $-.25^{\star \star \star}$ & $-.15^{\star *}$ \\
\hline Age & -.02 & -.07 & -.06 & -.03 & -.03 & -.08 & .00 & -.04 & -.03 \\
\hline $\begin{array}{l}\text { Explained } \\
\text { Variance } \mathrm{R}^{2}\end{array}$ & .19 & .20 & .08 & .33 & .21 & .17 & .42 & .19 & .17 \\
\hline
\end{tabular}

${ }^{* * *}: p<.001 ;{ }^{* *}: p<.01 ;{ }^{*}: p<.05$. 
Table 7: Predicting Violence: Genderspecific Analyses (Standardised Regression Coefficients; M = Male; F = Female)

\begin{tabular}{|c|c|c|c|c|c|c|c|c|c|c|}
\hline & \multicolumn{4}{|c|}{ Acceptance of violence } & \multicolumn{3}{|c|}{ Violent acts } & \multicolumn{3}{|c|}{ Victimization } \\
\hline & & German & Turkish & Norwegian & German & Turkish & Norwegian & German & Turkish & Norwegian \\
\hline \multirow{2}{*}{$\begin{array}{l}\text { Domestic maternal } \\
\text { violence }\end{array}$} & M & $.26^{\star *}$ & $.24^{* *}$ & .15 & $.38^{* * *}$ & .12 & .06 & $.54^{\star \star \star}$ & $.19^{*}$ & $.21^{* *}$ \\
\hline & $\mathrm{F}$ & $.29^{* \star *}$ & .03 & .10 & $.53^{\star * *}$ & $.15^{*}$ & $.13^{*}$ & $.50^{\star * *}$ & $.19^{*}$ & $.26^{\star * *}$ \\
\hline \multirow[t]{2}{*}{ Family Climate } & M & -.00 & -.04 & $-.18^{*}$ & -.13 & -.02 & -.06 & $-.18^{* *}$ & .00 & .09 \\
\hline & $\mathrm{F}$ & -.00 & .01 & .03 & .06 & $-.16^{*}$ & .03 & -.06 & $-.17^{*}$ & -.13 \\
\hline \multirow[t]{2}{*}{ Irritability } & M & $.25^{\star *}$ & $.34^{\star *}$ & .09 & $.28^{\star \star *}$ & $.32^{* * *}$ & $.26^{* *}$ & $.24^{\star \star *}$ & $.27^{\star *}$ & $.28^{* \star *}$ \\
\hline & $\mathrm{F}$ & $.23^{* *}$ & $.37^{\star * *}$ & $.26^{\star *}$ & $.19^{* *}$ & $.28^{* \star *}$ & $.32^{* * *}$ & .03 & $.19^{* *}$ & $.29^{* * *}$ \\
\hline \multirow{2}{*}{$\begin{array}{c}\text { Explained } \\
\text { Variance } \mathrm{R}^{2}\end{array}$} & M & .15 & .23 & .09 & .32 & .15 & .09 & .51 & .14 & .13 \\
\hline & $\mathrm{F}$ & .17 & .14 & .08 & .34 & .16 & .14 & .28 & .14 & .23 \\
\hline
\end{tabular}

${ }^{* * *}: p<.001 ;{ }^{* *}: p<.01 ;{ }^{*}: p<.05$.

Concerning victimisation in peer-contexts, it could be consistently shown that domestic violence, irritability and gender were significant predictors for each sample; especially for German youth domestic violence was a very strong predictor $(B=0.52)$ as it is documented in Table 6 and 7.

For the reason that gender was, in each sample one of the most influential predictors, we analysed the regression coefficients separately for each gender.

The relation between domestic maternal violence and the acceptance of violence were moderated by gender in the Turkish sample; domestic maternal violence was a significant predictor only for males. Concerning family environment and violence acceptance, this relation was also moderated by gender for the Norwegian sample: a negative family environment was a significant predictor for Norwegian males as was the relation of irritability and violence acceptance: here a heightened irritability was a significant predictor of accepting violence only among females.

Gender as a moderator was also found in the Turkish and Norwegian sample concerning the relationship between domestic maternal violence and violent acts: Experienced domestic violence was a significant predictor only for females. Also in the Turkish sample, the relation between family climate and active violence was moderated by gender: a negative family climate was a significant predictor only for females. Lastly, the relation between family climate and victimisation was moderated by gender in the German and Turkish sample: whereas a negative family climate was a significant predictor of victimisation for males in the German sample, this was valid only for females in the Turkish sample.
This gender-specific analysis indicated remarkabe differences in the explained variance rates in the Turkish group regarding the acceptance of violence (23 $\%$ vs. $14 \%$ ), and in the German and Norwegian group regarding victimisation (German sample: $51 \%$ vs. 28 $\% ; 13 \%$ vs. $23 \%$ Norwegian sample).

\section{DISCUSSION}

This article focused mainly on the comprehension of the associations between familial parental contexts and the dimensions of juvenile violence within cross cultural variations. Using consistent measurement techniques we could enable relatively valid comparisons: focusing on juveniles' perceptions we followed a basic insight of educational psychology that perceived parenting styles are more effective than the intentions of parents.

Accordingly, the results show very clearly beyond any cultural contextes: parenting styles which involve violent educational means are closely linked with juvenile violence, whereas parenting characterised by a positive emotional interaction between parent and child (positive family climate) seems to inhibit juvenile violence or serves as a protective factor. This has political and practical implications.

Furthermore, the study provided evidence for cultural differences as to the extent of domestic as well as juvenile violence. Whereas the differences between the German and Turkish pupils concerning their rates of violence were negligible, Norwegian pupils displayed consistently lower rates. This may be partly traced back to a heightened sensibility in Norway on issues of bullying at school and nationwide programs against bullying and violence which have been in place since the end of the nineties (Olweus, 1999). 
We could confirm the expectation that more Turkish than German and Norwegian pupils reported about domestic maternal violence. At the same time more Turkish than German and Norwegian juveniles were involved in violent offences; but in a surprising finding, the family climate was highest in the Turkish sample. These higher rates of domestic violence combined with a simultaneously high positive family climate in the Turkish sample demands further interpretations. It is conceivable that reactions to corporal punishment or domestic violence follow some specific culture-bound rules: cultural contexts, in which punishment is more tolerated, as emphasized by Parke (2002).

Obviously, punishment seems to occur in a context (e.g. positive family climate) that minimizes its negative impact. This may presuppose that using corporal punishment is merely seen as legitimate in the Turkish families, which may be inherent in a widely accepted cultural model of parent child-relations. If corporal punishment is matter-of-factly accepted by the majority of the community, parents may feel justified in battering and hence may regard this behaviour as normative (Gershoff, 2002). By itself, this can explain why parental aggression neither leads to an erosion of the ties between the child and his parent or to negative outcomes like own violent behaviour in the Turkish sample. Moreover, domestic violence seems to be a stronger risk factor for German juveniles. Our results are in line with the findings of Erkman and Rohner (2006) in Turkey, who pointed out that possibly not the corporal punishment per se leads to negative effects in childrens' development but punishment that is perceived as an expression of rejection.

These findings confirm previous research on the relationship between domestic and juvenile violence in Turkey and Germany (Uslucan, 2003; Uslucan \& Fuhrer, 2004; Uslucan, Fuhrer \& Rademacher, 2003). Despite the fact that corporal punishment is a lowbase-rate-phenomenon (Parke, 2002; Kaufman \& Zigler, 1993), which in consequence is difficult to predict (Lipsey \& Derzon, 1998), there were great differences between the three countries. One of the strengths of this study is the conclusion that abusive parenting is still a societal problem in the German sample, but much more in the Turkish sample, whereas domestic violence seems not to be a problem in Norwegian families. Besides there being less cultural tolerance towards domestic violence, this may be ascribed to the older age of the Norwegian sample: it could also be assumed that it was more difficult for them to remember violence experienced at home.
However, we should keep in mind that although most of the correlations were significant, which is due to the large sample size, more than half of them were smaller than $r=.30$; insofar as they indicated small or moderate effects.

To interpret the data more adequately, we should be cautious when referring only to culture for explaining differences: it is a matter of course that individual human behaviour does not completely conform to cultural prescriptions and prohibitions. It is also more informative to focus on risk factors within the specific groups. It could be supposed, especially for the Turkish sample, that mothers in the questionnaire sample were significantly younger than European mothers; and maternal youth is an important risk factor for aggressive methods of parenting besides other risks including low socioeconomic status and a lower educational level (Day, Peterson \& McCracken, 1998).

Moreover, the higher rates of domestic violence in Turkish families can be further interpreted with reference to higher numbers of children in Turkish families. There is evidence that as family size increases, the parenting stress and therefore the frequency of corporal punishment increases. (Flynn, 1994; Hashima \& Amato, 1994). Larger families in which the competition for attention and love from the parents are also greater, parents have less time and energy to engage in a democratic and emancipated parenting style, which involves more explanations and reasoning. Concerning these higher rates of domestic violence (but not juvenile violence), our cross-cultural study confirms the interethnic findings, which reports more violence in migrant parent-child relations (Pfeiffer, Wetzels \& Enzmann, 1999; Lösel \& Bliesener, 2003). At this point it is assumed that some dominant patterns of parenting styles in the culture of origin still remain in the migration context.

In addition to this our results are in line with metaanalyses of differential socialization (Lytton \& Romney, 1991), which found no significant differences in the corporal punishment meted out to boys or girls from parents in North America, but found that parents from non-Western countries used corporal punishment more often towards boys than girls. Notably, the result that Turkish males were more victimised than females is consistent with prior research on gender specific rates of domestic violence (Straus, 1994). These gender differences may reflect the tendency of boys to misbehave or to be more active than girls (Day, Peterson, McCracken, 1998). In their meta-analytic 
study, Lipsey and Derson (1998) found that gender (males were more aggressive than females) and ethnicity were among the strongest predictors of juvenile violence. Concerning violent offences, we can confirm this general trend.

In conclusion, this cross-cultural study has shown that juvenile conduct problems were pervasive in each of the countries studied, but the results indicated that, primarily for German juveniles, domestic violence was a strong risk factor for juvenile violence including active and passive forms of violence. Generally speaking, the proposed model fit best with the German sample.

Explaining the strong relationship between victimisation in childhood (domestic violence) and victimisation in peer-context, it can be assumed that in analogy with the concept of "learned helplessness" (Seligman, 1979), juveniles develop learned "victim careers". There seems to be a kind of "negative" transmission insofar as not only the active violent behaviour patterns of parents are transmitted, but also the own passive suffering from early childhood to adolescence. In spite of this, we should be cautious in postulating a causal link between domestic violence and the violent offences of juveniles; domestic violence can not only be a cause, but also a reaction to violence problems of juveniles; conduct problems of youngster can evoke a harsher discipline (Cohen \& Brook, 1995). Perhaps it may be understood as a reciprocal influence insofar as punishment is related to conduct problems, which in turn is related to further aggressive parental discipline, as Noack \& Kracke (2003) showed in a longitudinal German sample.

On the one hand, we should not ignore these rates of juvenile violence because there is a close relation between aggressive behaviour during adolescence, especially by an early onset of aggressive or criminal behaviour, and later on in life (Farrington, 1998; Moffitt, 1993). On the other hand, for an appropriate estimation and interpretation of these rates, we should be aware that involvement in physical aggression is very common among school-age children in many parts of the world, despite the learned cultural differences. Furthermore, there are usually remarkable differences between the various school-types as well. (Lösel, Bliesener \& Averbeck, 1999). Juvenile violence can probably be seen as a specific developmental pathway toward exploring the limits of their own bodies and forming strategies to handle social relations. Longitudinal and cross-cultural studies have to identify these developmental pathways throughout the life- course of persistent violent offenders (Moffitt, 1993) and their cultural variances; the research reported here is limited to a cross-sectional design.

On the methodological level it is important to keep in mind the limitations of self-reports by the perpetrator: besides the problem of memory lapses and the decreased reliability of retrospective data, it should be taken into account that the perpetrators may lie, minimise or overestimate the severity of violence, or perceive their own violence as justified and as such, not worth the commentary. Moreover, the accounts of victims may be influenced by the relationship between perpetrator and victim, which leads to lower report rates. This is especially the case in a familial context. These biases should be weighed against the interpretation of the data. The other way, resorting to official crime statistics e.g. does not solve the problem; the rise in the trends in juvenile crime may be due to a shifted focus of society's attention onto violent acts carried out by young people, especially in western Europe (Estrada, 2001). For example, the dramatic increase of violence in the schools is also due to a heightened alertness and to an increase in the number of reports of minor assaults. Nonetheless, as a warning against a crude culturalistic interpretation, it should be mentioned that neither culture can be conceived of as a static fixed entity (Keller et al., 2005), nor should the investigated regions of Magdeburg, Kayseri and Oslo and Tönsberg be seen as representative of Germany, Turkey and Norway.

To be more reliable, further research should use multiple informants and multiple methods such as questionnaires, observations and qualitative analyses. Moreover, for prevention efforts, the focus should be on detailing culture specific protective and risk factors which go beyond well known general risk factors. Finally, one of the main tasks of further research should lie in identification; why does not every child living in high violence and gang-ridden neighbourhood becomes violent? (Guerra, 1998) and why not every parent uses violence, although burdened with low education and low income, as well as a lack of parenting competencies. We need more studies on risks factors, but also on resilience.

\section{REFERENCES}

Barnett, O. W., Miller-Perrin, C. L., \& Perrin, R. D. (1997). Family violence across the lifespan. Thousand Oaks - London - New Delhi: Sage.

Björkquist, K., Lagerspetz, K. M., \& Kaukiainen, A. (1992). Do girls manipulate and boys fight? Developmental trends in regard 
to direct and indirect aggression. Aggressive Behaviour, 18, 117-127.

http://dx.doi.org/10.1002/1098-2337(1992)18:2<117::AIDAB2480180205>3.0.CO:2-3

Brennan, P. A., Mednick, B. R. A., \& Mednick, S. A. (1993). Parental psychopathology, congenital factors, and violence. In S. Hodgins (Ed.), Mental disorder and crime (pp. 244-261). Thousands Oaks, CA: Sage.

Cohen, P., \& Brook, J. S. (1995). The reciprocal influence of punishment and child behaviour disorder. In J. McCord (Ed.), Coercion and punishment in long-term perspectives (pp. 154164). New York: Cambridge University Press.

Coie, J. D., \& Dodge, K. A. (1997). Aggression and antisocial behaviour. In W.V. Damon (Ed.), Handbook of child development: Vol. 3. Social, emotional, and personality development (pp. 779-862). New York: Wiley.

Darling, N. \& Steinberg, L. (1993). Parenting style as context: an integrative model. Psychological Bulletin, 113, 487 - 496. http://dx.doi.org/10.1037/0033-2909.113.3.487

Day, R. D., Peterson, G. W., \& McCracken, C. (1998). Predicting Spanking of Younger and Older Children by Mothers and Fathers. Journal of Marriage and the Family, 60, 79-94. http://dx.doi.org/10.2307/353443

De Anda, D. \& Becerra, R. M. (2000) (Eds.). Violence. Diverse Populations and Communities. New York: Haworth Press.

Dodge, K. A., Murphy, R. R., \& Buchsbaum, K. (1984). The assessment of intention-cue detection skills in children: Implications for developmental psychopathology. Child Development, 55, 163-173. http://dx.doi.org/10.2307/1129842

Engfer, A. (2000). Gewalt gegen Kinder in der Familie. In U. T. Egle, S. O. Hoffmann \& P. Joraschky (Eds.), Sexueller Mißbrauch, Mißhandlung und Vernachlässigung (pp. 23-40). Stuttgart: Schattauer.

Erkman, F. \& Rohner, R. P. (2006). Youths` Perceptions of Corporal Punishment, Parental Acceptance and Psychological Adjustment in a Turkish Metropolis. Jcross-Cultural Research, 40, 250-267. http://dx.doi.org/10.1177/1069397106287924

Estrada, F. (2001). Juvenile violence as a social problem. Trends, media attention and societal response. British Journal of Criminology, 41, 639 - 655. http://dx.doi.org/10.1093/bjc/41.4.639

Farrington, D. P. (1998). Predictors, causes, and correlates of male youth violence. In M. Tonry \& M. H. Moore (Eds.), Youth violence (pp. 421-475). Chicago: University of Chicago.

Flynn, C. P. (1994). Regional differences in attitudes toward corporal punishment. Journal of Marriage and the Family, 56, 314 324. http://dx.doi.org/10.2307/353102

Garbarino, J., \& Ebata, A. (1983). The Significance of Ethnic and Cultural Differences in Child Maltreatment. Journal of Marriage and the Family, 45, 773-783. http://dx.doi.org/10.2307/351790

Gershoff, E. T. (2002). Corporal punishment by parents and associated child behaviors and experiences: a meta-analytic and theoretical review. Psychological Bulletin, 128, 539-579. http://dx.doi.org/10.1037/0033-2909.128.4.539

Gunnoe, M. L., \& Mariner, C. L. (1997). Toward a DevelopmentalContextual Model of the Effects of Parental Spanking on Children's Aggression. Arch Pediatr Adolesc Med 151, 768775 http://dx.doi.org/10.1001/archpedi.1997.02170450018003

Guerra, N. G. (1998). Serious and Violent Juvenile Offenders: Gaps in Knowledge and Research Priorities. In R. Loeber \& D. P. Farrington (Eds.), Serious and violent juvenile offenders (pp. 389-404). Thousands Oaks, CA: Sage.
Hashima, P. Y., \& Amato, P. R. (1994). Poverty, social support, and parental behaviour. Child Development, 65, 394 - 403. http://dx.doi.org/10.2307/1131391

Hortacsu, N., Kalaycioglu, S., \& Rittersberger-Tilic, H. (2003). Intrafamily aggression in Turkey: frequency, instigation, and acceptance. Journal of Social Psychology, 143, 163-184. http://dx.doi.org/10.1080/00224540309598438

Hirschi, T. (1969). Causes of Delinquency. Berkeley, CA: University of California Press.

Kagitcibasi, C. (1997). Individualism and collectivism. In J. W. Berry, M. H. Segall \& C. Kagitcibasi (Eds.), Handbook of crosscultural psychology, Vol. 3: Social behaviour and applications (pp. 1-49). Boston: Allyn \& Bacon.

Kagitcibasi, C., Sunar, D. \& Bekman, S. (1988). Comprehensive Prescool education project: Final report (manuskript report 209e). Ottawa, Canada: International Development Research Center.

Kagitcibasi, C., \& Sunar, D. (1997). Familie und Sozialisation in der Türkei. In B. Nauck, U. Schönpflug (Eds.), Familien in verschiedenen Kulturen (pp. 145-161). Stuttgart: Enke.

Kalmus, D. (1984). The intergenerational transmission of marital aggression. Journal of Marriage and the Family, 46, 11-19. http://dx.doi.org/10.2307/351858

Kaufman, J., \& Zigler, E. (1993). The intergenerational transmission of abuse is overstated. In R. J. Gelles \& D. R. Loseke (Eds.) Current controversies on family violence (pp. 209-221). Thousand Oaks - London - New Delhi: Sage.

Keller, H., Borke, J., \& Yovsi, R. (2005). Cultural orientations and historical changes as predictors of parenting behaviour. International Journal of Behavioral Development, 29, 229237.

Klinteberg, B. A. et al. (1993). Hyperactive behaviour in childhood as related to subsequent alcohol problems and violent offending: a longitudinal study of male subjects. Personality and individual differences, 15, 381-388.

http://dx.doi.org/10.1016/0191-8869(93)90065-B

Lipsey, M. W., \& Derzon, J. H. (1998). Predictors of Violent or Serious Delinquency in Adolescence and Early Adulthood: A Synthesis of Longitudinal Research. In R. Loeber \& D. P. Farrington (Eds.), Serious and violent juvenile offenders (pp. 86-105). Thousands Oaks, CA: Sage.

Loeber, R., \& Hay , D. (1997). Key issues in the development of aggression and violence from childhood to early adulthood. Annual Review of Psychology, 48, 371-410. http://dx.doi.org/10.1146/annurev.psych.48.1.371

Loeber, R., \& Farrington, D. P. (1998) (Eds.), Serious and violent juvenile offenders. Thousands Oaks, CA: Sage.

Loeber, R., \& Stouthamer-Loeber, M. (1986). Family factors as correlates and predictors of juvenile conduct problems and delinquency. In M. Tonry and N. Morris (Eds.), Crime and justice, Vol. 7 (pp. 29-149). Chicago: University of Chicago Press.

Lösel, F., Bliesener, T., \& Averbeck, M. (1999). Hat die Delinquenz von Schülern zugenommen? Ein Vergleich im Dunkelfeld nach 22 Jahren. In M. Schäfer \& D. Frey (Eds.), Aggression und Gewalt und Kindern und Jugendlichen (pp. 65-90). Göttingen: Hogrefe.

Lösel, F., \& Bliesener, T. (2003). Aggression und Delinquenz unter Jugendlichen. Neuwied: Luchterhand.

Lytton, H., \& Romney, D. M. (1991). Parents' differential socialization of boys and girls: A meta analysis. Psychological Bulletin, 109, 267-296. http://dx.doi.org/10.1037/0033-2909.109.2.267

Malley-Morrison, K., \& Hines, D. A. (2004) (Eds.), Family Violence in a Cultural Perspective. Thousand Oaks, CA: Sage. 
Markus, H. R., \& Kitayama, S. (1991). Culture and the self: Implications for cognition, emotion, and motivation. Psychological Review, 98, 224-253. http://dx.doi.org/10.1037/0033-295X.98.2.224

McCord, J. (1995). Coercion and punishment in long-term perspectives. New York: Cambridge University Press.

Melzer, W. (2000). Gewaltemergenz - Reflexionen und Untersuchungsergebnisse zur Gewalt in der Schule. Psychosozial, 23, 6-15.

Moffitt, T. E. (1993). Adolescence-limited and life-course-persistent antisocial behaviour: A developmental taxonomy. Pschological Review, 100, 674-701. http://dx.doi.org/10.1037/0033-295X.100.4.674

Noack, P., \& Kracke, B. (2003). Elterliche Erziehung und Problemverhalten bei Jugendlichen. Analysen reziproker Effekte im Längsschnitt. Zeitschrift für Familienforschung, 1, 25-37.

Nobes, G., Smith, M., Upton, P., \& Heverin, A. (1999). Physical punishment by mothers and fathers in British homes. Journal of Interpersonal Violence, 14, 887-902. http://dx.doi.org/10.1177/088626099014008006

Olweus, D. (1993). Bullying at school: What we know and what we can do. Oxford: Cambridge.

Olweus, D. (1999). Norway. In P. K. Smith et al. (Eds.), The nature of school bullying: A cross-national perspective (pp. 28-48). London: Routledge.

Patterson, G. R., DeBaryshe, B. D., \& Ramsey, E. (1989). A developmental perspective on antisocial behavior. American Psychologist, 44, 329-335. http://dx.doi.org/10.1037/0003-066X.44.2.329

Parke, R. D. (2002). Punishment revisited - Science, Values, and the Right Question: Comment on Gershoff (2002). Psychological Bulletin, 128, 596-801. http://dx.doi.org/10.1037/0033-2909.128.4.596

Parke, R. D., \& Slaby, R. G. (1983). The development of aggression. In E. M. Hetherington (Ed.), Socialisation, personality, and social development (pp. 547-641). New York: Wiley.

Pfeiffer, C., Wetzels, P. \& Enzmann, D. (1999). Innerfamiliäre Gewalt gegen Kinder und Jugendliche und ihre Auswirkungen. KFN Forschungsberichte Nr. 80. Hannover: KFN.

Rohner, R. P., Kean, K. J., \& Cournoyer, D. E. (1991). Effects of corporal punishment, perceived caretaker warmth, and cultural beliefs on the psychological maladjustment of children in St. Kitts, West Indies. Journal of Marriage and the Family, 58, 681-693. http://dx.doi.org/10.2307/352743

Schwartzman, A. E.; Verlaan, P., Peters, P., \& Serbin, L. A. (1995). Sex roles as coercion. In J. McCord (Ed.), Coercion and punishment in long-term perspectives (pp. 362-375). New York: Cambridge University Press.

Seligman, M. E. P. (1979). Erlernte Hilflosigkeit. München: Urban \& Schwarzenberg.

Simons, R. L., Whitbeck, L. B., Conger, R. D., \& Chyi-In, W. (1991). Intergenerational transmission of harsh parenting. Developmental Psychology, 27, 159-171.

http://dx.doi.org/10.1037/0012-1649.27.1.159
Straus, M. A. (1979). Measuring intrafamily conflict and violence: The Conflict Tactics Scales (CTS). Journal of Marriage and the Family, 41, 75-88. http://dx.doi.org/10.2307/351733

Straus, M. A. (1994). Beating the devil out of them: Corporal punishment in American families. New York: Lexington.

Straus, M. A., \& Mathur, A. K. (1996). Social Change and the Trends in Approval of Corporal Punishment by Parents from 1968 to 1994. In D. Frehsee, W. Horn \& K.- D. Bussmann (Eds.), Family Violence Against Children (pp. 91-105). Berlin - New York: de Gruyter.

Straus, M. A., Gelles, R. J., \& Steinmetz, S. (1980). Behind closed doors: Violence in the American family. NY: Doubleday.

Straus, M. A., \& Stewart, J. H. (1999). Corporal punishment by American parents: National data on prevalence, chronicity, severity, and duration, in relation to child and family characteristics. Clinical Child and Family Psychology Review, 2, 55-70. http://dx.doi.org/10.1023/A:1021891529770

Sturzbecher, D. (1997). Jugend und Gewalt in Ostdeutschland. Göttingen: Verlag für Angewandte Psychologie.

Thronberry, T. P. (2009). The apple doesn't fall far from the tree (or does it?): Intergenerational patterns of antisocial behaviour. Criminology, 47, 2, 297-325.

Tolan, P. H. (1987). Implications of Age of Onset for Delinquency Risk. Journal of Abnormal Child Psychology, 15, 47-65. http://dx.doi.org/10.1007/BF00916465

Uslucan, H.-H. (2003). Soziale Verunsicherung, Familienklima und Gewaltbelastung türkischer Jugendlicher. Zeitschrift für Türkeistudien, 15, 49-73.

Uslucan, H.-H., Fuhrer, U., \& Rademacher, J. (2003). Jugendgewalt und familiale Desintegration. Psychologie in Erziehung und Unterricht, 50, 281-293.

Uslucan, H.-H., \& Fuhrer, U. (2004). Viktimisierungen und Gewalthandlungen im Jugendalter. Psychologie in Erziehung und Unterricht, 51, 178-188.

Van de Vijver, F., \& Leung, K. (1997). Methods and data analysis for cross-cultural research. California: Sage.

Wetzels, P. (1997). Gewalterfahrungen in der Kindheit. BadenBaden: Nomos.

Wilmers, N., Enzmann, D., Schaefer, D., Herbers, K., Greve, W., \& Wetzels, P. (2002). Jugendliche in Deutschland zur Jahrtausendwende: Gefährlich oder gefährdet? Ergebnisse wiederholter, repräsentativer Dunkelfelduntersuchungen zu Gewalt und Kriminalität im Leben junger Menschen 19982000. Baden-Baden: Nomos.

http://www.aile.gov.tr/Arastirma12.htm

http://www.aile.gov.tr/Arastirma18.htm

http://www.kriminoloji.com/siddet\%20cocuk.htm

Received on 07-05-2013

Accepted on 12-06-2013

Published on 12-07-2013

\section{DOI: http://dx.doi.org/10.6000/1929-4409.2013.02.24}

(C) 2013 Haci-Halil Uslucan; Licensee Lifescience Global.

This is an open access article licensed under the terms of the Creative Commons Attribution Non-Commercial License (http://creativecommons.org/licenses/by-nc/3.0/) which permits unrestricted, non-commercial use, distribution and reproduction in any medium, provided the work is properly cited. 